\title{
Implementation of CCDC to produce the LCMAP Collection 1.0 annual land surface change product
}

George Z. Xian ${ }^{1}$, Kelcy Smith ${ }^{2}$, Danika Wellington ${ }^{2}$, Josephine Horton ${ }^{2}$, Qiang Zhou ${ }^{3}$, Congcong $\mathrm{Li}^{3}$, Roger Auch ${ }^{1}$, Jesslyn F. Brown ${ }^{1}$, Zhe Zhu' ${ }^{4}$, and Ryan R. Reker ${ }^{2}$

${ }^{1}$ United States Geological Survey (USGS) Earth Resources Observation and Science (EROS) Center, Sioux Falls, South Dakota 57198, U.S.A.

${ }^{2}$ KBR, Contractor to the USGS EROS Center, Sioux Falls, SD, 57198, U.S.A.

${ }^{3}$ ASRC Federal Data Solutions (AFDS), Contractor to the USGS EROS Sioux Falls, SD 57198, U.S.A.

${ }^{4}$ Department of Natural Resources and the Environment, University of Connecticut, Storrs, CT, U.S.A. Correspondence: George Xian (xian@usgs.gov) 


\section{Introduction}

The characteristics of land surface fundamentally connect with the functioning of Earth's terrestrial surface. Changes in land cover and land surface are one of the greatest and most immediate influences on the Earth system and these changes will continue in association with a surging human population and growing demand on land resources (Szantoi et al., 2020). Changes in land cover and ecosystems and their implications for global environmental change and sustainability are major research challenges for developing strategies to respond to ongoing global change while meeting development goals (Turner II et al., 2007). Unknowns related to the spatial extent and degrees of impacts of anthropogenic activities on natural systems and strategies to respond to ongoing global change hinder efforts to overcome sustainability challenges (Erb et al., 2017; Reid et al., 2010). An improved understanding of the complex and dynamic interactions between the various Earth system components, including humans and their activities, is critical for policymakers and scientists (Foley, 2005; Foley et al., 2011). To fully understand these processes and monitor these changes, accurate and frequently updated land cover information is essential for scientific research and to assist decision makers in responding to the challenges associated with competing land demands and land surface change.

Satellite observations have been used to observe the Earth's surface and to characterize land cover and change from local to global scales. Remote sensing data allows us to obtain information over large areas in a practical and accurate manner. With advanced technologies and accumulating satellite data, countries and regions have produced multi-spatial and multitemporal resolution land cover products (Chen et al., 2015; Gong et al., 2020; Hansen, 2013; Homer et al., 2020; Li et al., 2020). A variety of land change mapping has been carried out to produce land cover and change products in the United States. Among these efforts are the widely known National Land Cover Database (NLCD) products. NLCD has provided comprehensive, general-purpose land cover mapping products at 30-m resolution since 2001 in the United States, and the products have been published and updated across more than a decade (Homer et al., 2020). NLCD provides Anderson Level II land cover classification (Anderson, 1976) for the conterminous United States (CONUS) at approximately 2-3-year intervals. Other national-scale mapping projects focus on specific land cover themes. Among these are the Landscape Fire and Resource Management Planning Tools (LANDFIRE) (Picotte et al., 2019), which maps 
vegetation and fuels in support of wildfire management, and the Cropland Data Layer (Boryan et al., 2011) generated by the National Agricultural Statistics Service (NASS) of the United States Department of Agriculture (USDA). Due to the need to incorporate data from neighboring years, as well as extensive post-processing, ancillary dataset dependencies, and analyst-supported refinement, release dates for both LANDFIRE and NLCD products are typically several years subsequent to the nominal map year. Other products including national urban extent change and vegetation phenology data are available ( $\mathrm{Li}$ et al., 2019; Li et al., 2020). These projects vary in how land change information is incorporated or expressed across product releases. Continuous data stacks allow for an increase in input features for land cover classification. Frequent data also provides the opportunity for near-real time change monitoring with frequently updated image acquisitions. The availability of land change information has led to approaches that attempt to monitor surface properties continuously through time. Such approaches have several advantages over traditional image processing techniques based on small numbers of images (Bullock et al., 2020; Zhu and Woodcock, 2014b).

Leveraging the increasingly massive amount of openly available, analysis-ready data products into the generation of operational land cover and land change information has been described as the new paradigm for land cover science (Wulder et al., 2018). The approach, which intended to use all available medium resolution remotely sensed data from the 1980 s to the present, opened a door for the scientific community to integrate time series information to improve change detection and land cover characterization in a robust way. Furthermore, change events, when combined with knowledge of ecology settings or anticipation of a given process post-change, can accommodate consistent change observations and characterization of land cover. For example, forest areas that are cleared by wildfire or harvest activities typically transfer to non-forest herbaceous or shrub vegetation cover, followed by a succession of young tree stages, ultimately returning to a forest class. Traditional change detection methods using limited observations may not have identified these changes if data were collected with a starting date prior to the change and an ending date that occurred after the transitional (non-tree) vegetation returned to tree cover. Therefore, incorporating change information into the land cover characterization process allows for insights regarding expected land cover class transitions related to successional processes, and likewise provides a mechanism to identify illogical class transitions and cause or agent of change (Kennedy et al., 2015; Wulder et al., 2018). The choice of a time series 
approach also allows missing data and phenological variations to be handled robustly (Friedl et al., 2010; Wulder et al., 2018).

The Continuous Change Detection (CCD) and Classification (CCDC) algorithm (Zhu and Woodcock, 2014b; Zhu et al., 2015b) was developed to advance time series change detection by using all available Landsat data. The CCD algorithm uses robust methodology to identify when and how the land surface changes through time. The algorithm first estimates a time series model based on clear observations and then detects outliers by comparing model estimates and Landsat observations. The algorithm fits harmonic regression models through a Least Absolute Shrinkage and Selection Operator (LASSO) (Tibshirani, 1996) approach to every pixel over time to estimate the time series model defined by sine and cosine functions. New Landsat records are compared to predicted results, and if the observed data deviate beyond a set threshold for all records within a moving window period, then a model break is produced. The parameters used to fit the model are used as inputs for the cover classifier for land cover characterization.

The original implementation of CCDC was written in the MATLAB programming language and had been implemented for a regional land cover change assessment in the eastern CONUS (Zhu and Woodcock, 2014b). The algorithm includes the automation of change detection/classification and can monitor changes for different land cover types. The implementation of CCDC into a large geographic extent still encounters several challenges: the availability of Landsat records and training datasets, the effectiveness of choosing good quality Landsat records, and the robustness to characterize land cover and change across various land cover types and conditions. In this paper, we outlined major efforts and challenges in the implementation of CCDC for the U.S. Geological Survey (USGS) Land Change Monitoring, Assessment, and Projection (LCMAP) initiative (Brown et al., 2020). LCMAP focuses on using CCD/CCDC with time series Landsat records and other ancillary information to produce annual land cover and change products from 1985 to the present for the United States. We focused on how LCMAP employed every observation in a time series of U.S. Landsat Analysis Ready Data (ARD) (Dwyer et al., 2018) over a long period starting with the 1980s to determine whether change occurred at any given point in the observation record. The algorithm was further used to classify the pixel to indicate what land cover type(s) were observed before and after a detected change on the land surface. The CCDC algorithm has since been translated into an open-source library as Python 
code. The full implementation joined the CCD Python library with the classification methodology in combination with data delivery/processing services made available through the LCMAP Information Warehouse and Data Store (IW+DS).

\section{Data Sources}

The CCDC algorithm utilizes all available Landsat observations including surface reflectance, brightness temperature, and associated quality data to characterize the spectral responses of every pixel through harmonic regression model fits. The model fits are then used to categorize each pixel time series into temporal segments of stable periods and to estimate the dates at which the spectral time-series data diverge from past responses or patterns. The outcomes of model fits and other input data are then used for classification. The algorithm requires several input datasets to perform both change detection and classification.

\subsection{Landsat observations}

U.S. Landsat ARD have been processed to a minimum set of requirements and organized into a form that can be more directly and easily used for monitoring and assessing landscape change with minimal additional user effort. Landsat ARD Collection 1 provides consistent radiometric and geometric Landsat products across Landsat 4-5 Thematic Mapper (TM), Landsat 7 Enhanced Thematic Mapper Plus (ETM+), and Landsat 8 Operational Land Imager (OLI) / Thermal Infrared Sensor (TIRS) instruments for use in time series analysis (Dwyer et al., 2018). Landsat ARD is organized in tiles, which are units of uniform dimension bounded by static corner points in a defined grid system (Fig. 1). An ARD tile is currently defined as 5,000 x 5,000 30-meter (m) pixels or 150 x 150-kilometer $(\mathrm{km})$. To implement CCDC algorithms to produce LCMAP Collection 1.0 land change products in CONUS, all available Landsat ARD records of surface reflectance and brightness temperature from the 1980s to 2017 were required.

\subsection{Land cover and ancillary datasets}

The CCDC algorithm employs every observation in a time series of Landsat data to determine whether change has occurred at any given time. The algorithm further classifies the time series to indicate what land cover types were observed before and after a detected change and further to generate LCMAP annual land cover products (Table 1). The land cover products are produced by 
using training data from NLCD in 2001. NLCD provides Anderson Level II (Anderson, 1976) land cover classification for CONUS and outlying areas (Homer et al., 2020). Spectral index and change metrics between cloud-corrected Landsat mosaics are used, among other information, to identify change pixels (Jin et al., 2013). These metrics allow NLCD to incorporate temporal and spectral trajectory information into both training data selection and final land cover classification. The NLCD land cover data is used in LCMAP as land cover training data. Ancillary data comprises two main source datasets: the USGS National Elevation Dataset (NED) (Gesch et al., 2002) 1 arc-second Digital Elevation Models (DEM), and a wetland potential index (WPI) layer created for NLCD 2011 land cover production (Zhu et al., 2016). The WPI layer is a ranking (0-8) of wetland likelihood from a comparison of the National Wetland Inventory (NWI), the U.S. Department of Agriculture Soil Survey Geographic Database (SSURGO) for hydric soils, and the NLCD 2006 wetlands land cover classes.

\section{Methodology}

As part of the operational LCMAP system, the original MATLAB version of the CCDC algorithm is converted to a format that meets the needs of large-scale land change detection and change characterization on an annual basis. Python is selected to replace MATLAB to implement the CCDC algorithm for LCMAP. The CCD component of the CCDC algorithm is converted to create the Python-based CCD (PyCCD) library. The PyCCD library is a per-pixel algorithm, and the fundamental outputs are the spectral characterizations (segments) of the input data. There are several key components in PyCCD. The overall CCD procedures are summarized in Fig. 2.

\subsection{Data filtering and Harmonic modeling}

The removal of invalid and cloud-contaminated data points is important for deriving model coefficients that accurately represent the phenology of the surface, and for the correct identification of model break points. The CCD algorithm uses Landsat ARD PIXELQA values to mask observations identified as cloud, cloud shadow, fill, or (in some cases) snow derived based on the Fmask 3.3 algorithm (Zhu et al., 2015a; Zhu and Woodcock, 2012). Additional cirrus and terrain occlusion bits are provided for Landsat 8 OLI-TIRS ARD that are not available in the 
Landsat 4-7 TM/ETM+ quality assessment band. To maintain consistency across the historical archive, the algorithm does not rely on these Landsat 8-only QA flags to filter out observations. Landsat ARD containing invalid or physically unrealistic data values are removed. For the surface reflectance bands, the valid data range is between 0 and 10000. Brightness temperature values, which in the ARD are stored as $10 \times$ temperature (kelvin), are converted to $100 \times{ }^{\circ} \mathrm{C}$ and observations are filtered for values outside the range -9320 and $7070\left(-93.2-70.7^{\circ} \mathrm{C}\right)$. This procedure rescales the brightness temperature values into a roughly similar numerical range as the surface reflectance bands. A multitemporal mask (Tmask) model (Zhu and Woodcock, 2014a) is implemented first to remove additional outliers by using the multitemporal observation record to identify values that deviate from the overall phenology curve using a specific harmonic model to perform an initial fit to the phenology. Additional details are provided in the Supplementary materials S1.

The filtered Landsat ARD is further operated to generate the time series fit by harmonic models whose sinusoidal components are frequency multiples of the base annual frequency. A constant and linear term characterizes the surface reflectance or brightness temperature offset value and overall slope, respectively. The full harmonic model is defined as follows:

$\hat{p}(i, t)=c_{0, i}+c_{1, i} t+\sum_{n=1}^{3}\left(a_{n, i} \cos \omega n t+b_{n, i} \sin \omega n t\right)$

where $\omega$ is the base annual frequency $(2 \pi T), t$ is the ordinal of the date when January 1 of the year zero has ordinal 1 (sometimes called Julian date), $\mathrm{i}$ is the ith Landsat band, $\mathrm{a}_{\mathrm{n}, \mathrm{i}}$ and $\mathrm{b}_{\mathrm{n}, \mathrm{i}}$ are the estimated $n t h$ order harmonic coefficients for the ith Landsat band, $\mathrm{c}_{0, \mathrm{i}}$ and $\mathrm{c}_{1, \mathrm{i}}$ are the estimated intercept and slope coefficients for the ith Landsat band, and $\hat{p}(i, t)$ is the predicted value for the ith Landsat band at ordinal date t. Model initialization and certain special-case regression fits such as at the beginning/end of the time series use the simple four-coefficient model. Outside of these conditions, the selection of coefficient depends on the number of observations used for the regression. For a full model (eight coefficients), there must be at least 24 observations covered by the regression. The fit parameters returned by PyCCD always include eight coefficient values including an intercept, with unused coefficients reported as zeroes.

\subsection{Regression models and change detection thresholds}


The best-fit coefficients for the time series model are calculated using a LASSO regression model (Tibshirani, 1996). In contrast to Ordinary Least Squares (OLS) that was used in the original CCDC development, LASSO penalizes the sum of the absolute values of coefficients, in some cases forcing a subset of the coefficients to zero. Together with the explicit limits enforced on the number of coefficients, this reduces instances of overfitting, including in cases when observations are too sparse or unevenly distributed in time to constrain the model to real phenological features. To detect change, the LASSO model checks CCD model breaks with respect to its last determined best-fit harmonic model.

To correctly detect change, the algorithm distinguishes between a substantive deviation from model prediction and deviations that result from variability inherent in the data (due to incomplete atmospheric removal and/or other sources of natural variation) to detect change. The algorithm calculates two parameters related to dispersion, or scatter, to estimate the variability of data for each spectral band. The first one is a comparison root-mean-square-error (RMSE) that is the RMSE of the 24 observations covered by the model which are closest in day of year to the last observation in the "peek window," or over all observations covered by the model if there are fewer than 24. This value is recalculated at each step of the time series. The second parameter (var) is used to measure the overall variability of the data values and is defined as the median of the absolute value of the differences between each observation and the ith successive observation, where $\mathrm{i}$ is the smallest value such that the majority of these observation pairs are separated by greater than 30 days, if possible (otherwise, $\mathrm{i}=1$ ). The var is computed once at the beginning of the standard procedure, using all non-masked observations in the time series.

Observations not yet incorporated into the model are evaluated as a group of no fewer than the PEEK_SIZE parameter value; this is the "peek window," which "slides" along the time series one observation at a time. Each iteration, a value is calculated for each individual observation within the peek window, as follows:

$$
\operatorname{mag}_{n}=\sum_{i \in D}\left(\frac{\operatorname{resid}_{n, i}}{\max \left(\operatorname{var}_{i}, R M S E_{i}\right)}\right)^{2}
$$

where, resid $_{n, i}$ is the residual relative to the LASSO models for each band $i$, for each observation $n$ within the PEEK_SIZE window, var $_{i}$ and $R M S E_{i}$ are the parameters of dispersion as described above, for each band $i$. This summation is carried out for all bands $i$ in the set of 
DETECTION_BANDS $(D)$. This produces a scalar magnitude, representing the deviation from model prediction across these bands, for each observation. The detection of a model break requires this value to be above the CHANGE_THRESHOLD value for all observations in the window. This is separate from the value that is reported as a per-band magnitude when a change is detected in the time series. Change detection sensitivity depends on the value of change threshold. The CHANGE_THRESHOLD is determined in Eqs. S2 and S3 in the Supplementary. If $\mathrm{mag}_{n}<$ CHANGE_THRESHOLD for any $n$ in the Peek_Size window, then add the most recent observation to the segment by shifting the Peek_Size window one observation forward in the time series. If $\operatorname{mag}_{n}>$ CHANGE_THRESHOLD for all $n$ in the Peek_Size window, this is considered a spectral break.

\subsection{Permanent snow and insufficient clear observation procedures}

The permanent snow procedure indicates that too few clear (less than $25 \%$ of total observations) or water observations, which are identified from the QA band, exist to robustly detect change, and a large fraction of observations are snow. The algorithm will return at most one segment that fits through the entire time series and provide the filtered observations number at least twelve. The model will, under the default settings, fit only four coefficients (i.e., characterizing the reflectance and brightness temperature bands using only a simple harmonic with no higher frequency terms). Unlike other procedures, snow pixels are not filtered out and are fit as part of the annual pattern. This avoids overfitting the model to a seasonally sparse observation record. Similarly, for the insufficient clear observations determined by the QA band, the model will perform a LASSO regression fit for the entire time series using four coefficients. The model coefficients and RMSE from this regression are recorded. Additional parameters including the start, end, and observation count are also saved. Further, the change Boolean value is set to 0 , and the break day is recorded as the last observation date. The magnitude of change as zero for each band is also saved.

\subsection{Land cover classification}

The CCDC algorithm characterizes the land cover component of a pixel at any point using the LCMAP time series model approach from the Landsat 4-8 records. The classification of CCDC is accomplished for every pixel based on data from the time series models (e.g., model 
coefficients). Land cover classifications are generated on an annual basis, using July 1 st as a representative date. A list of land cover classes and descriptions is provided in Table 1.

\subsubsection{Classification algorithm}

We chose eXtreme Gradient Boosting (XGBoost) (Chen and Guestrin, 2016) as the classification method. XGBoost is a scalable implementation of gradient tree boosting, which is a supervised learning method that can be used to develop a classification model when provided with an appropriate training dataset. Generally, for a given dataset, a tree ensemble model uses additive functions, which correspond to independent tree structures, to predict the land cover. The predictions from all trees are also normalized to the final class probabilities using the softmax function. The algorithm can handle sparse data and theoretically justify weighted quantile sketch for approximate learning. The resultant trained model can be applied to a larger dataset to generate predictions and probability scores which are the basis for LCMAP primary and secondary land cover types. The primary and secondary land cover confidence values are calculated from these scores.

\subsubsection{Training dataset}

The training data used in XGBoost for the LCMAP Collection 1.0 land cover products is from the USGS NLCD 2001 land cover product (Homer et al., 2020). To meet the LCMAP land cover legend, the NLCD data is first cross-walked to LCMAP classes, as shown in Fig.3 and Table 2. The extent of each land cover in the cross-walked NLCD layer is eroded by one pixel. This step aims to reduce potential noise in the classifier by removing pixels that may be heavily mixed with different cover types, or whose land cover label may be less reliable. It also removes the narrow linear low-intensity developed pixels corresponding to road networks, which were found to have registration issues with Landsat ARD in some areas.

\subsubsection{Ancillary data}

Ancillary data used in the classification contains two main datasets: the DEM and the WPI layer. Three DEM derivative datasets are implemented as geographic references for land cover classification as ancillary data including topographic slope, aspect, and position index. The WPI 
325 is highly related to wetland distribution and has a potential to improve wetland classification in

326 LCMAP.

$327 \quad 3.4 .4$ Classification procedures

328 For each pixel, CCD segment data for the segment that includes the July 1st, 2001 date is used

329 with training data to create classification models (Zhou et al., 2020; Zhu et al., 2016). The CCD model data used with training data include the model coefficients (except the intercepts) generated from surface reflectance and brightness temperature bands, the model RMSE value for each band, and an average intercept value that is calculated from average annual reflectance values for each band for the July 1, 2001 year. The model training procedure is conducted at the tile level, using random samples drawn from the targeted tile as well as the eight surrounding tiles to avoid not having enough training samples of rare land cover types in the targeted tile. Cross-walked and eroded NLCD data are used for classification labels, while the CCD model outputs and ancillary data are provided as independent variables. Based on training data testing using different sample sizes, a target sample size of 20 million pixels from the extent of $3 \times 3$ ARD tiles is chosen, requiring approximately proportional representation of classes with the added constraint that no class be represented by fewer than 600,000 or more than 8 million samples. If there are fewer than 600,000 samples available for a class, then all of the available samples are used without any oversampling. The XGBoost hyperparameters are selected as: maximum tree depth 8; fast histogram optimized approximate greedy algorithm for tree method; multiclass logloss for evaluation metric; and maximum number of rounds 500 .

After the classification models in a given tile are trained, predictions are generated for each July 1st date that has an associated CCD segment (Fig. 4). The prediction information is supplied to the production step for the creation of land cover. The process is repeated for each tile for the entire CONUS ARD extent.

\subsection{Validation data}

The LCMAP land cover product is validated using an independent reference dataset. The reference data, which consists of $24,97130 \mathrm{~m}$ x $30 \mathrm{~m}$ pixels selected via a simple random sampling method over CONUS, is collected from these sample plots between 1985 and 2017. The TimeSync tool is used to efficiently display Landsat data for interpretation and to record 
these interpretations into a database (Cohen et al., 2010; Pengra et al., 2020a). TimeSync displays the input Landsat images in two basic ways: by annual time-series images and by pixel values plotted through time. For the image display, single 255 x 255 -pixel subsets of Landsat images in the growing season are displayed in sequence from 1984 to 2018. Trained interpreters have access to all available images in each year to collect attributes in three basic categories: 1) land use, 2) land cover, and 3) change processes. Additional attribute details for the change processes, such as clear-cut and thinning associated with harvest events, are also collected. The interpreters manually label these attributes using Landsat 5, 7, and 8 imagery, high-resolution aerial photography, and other ancillary datasets (Cohen et al., 2010; Pengra et al., 2020a). Interpreters also use ancillary data to support interpretation of Landsat and high-resolution imagery, although Landsat data takes the highest weight of evidence. Recording the full set of attributes in land use, land cover, and land change categories provides sufficient information to meet the needs of LCMAP as well as other potential users. Quality assurance and quality control (QA/QC) processes are also implemented to ensure the quality and consistency of the reference data among interpreters and over the time span of data collection (Pengra et al., 2020a). The collected samples are then cross-walked to the appropriate LCMAP land cover class, providing a single land cover reference label for each year of the time series for each sample pixel.

The validation analysis protocols focus on estimating the confusion matrix and overall, user's, and producer's accuracy by comparing the reference data and product data labels. Overall accuracy and producer's accuracy as well as standard errors are produced using post stratified estimators (Card, 1982; Stehman, 2013). For accuracy estimates that are produced by combining multiple years of data, the sampling design is treated as a one-stage cluster sample where each pixel represents a cluster and each year of observation is the secondary sampling unit using cluster sampling standard error formulas (Pengra et al., 2020). The validation is only performed for primary land cover and change products, not for other LCMAP science products (Supplementary Section 4).

\subsection{Information warehouse and data store}

The LCMAP adopts an information warehouse and data store (IW+DS) system that can expand storage solutions along with data access and discovery services running on the EROS Shared Mesos Cluster. The system provides different storage solutions to allow for flexibility in 
choosing what best fits a dataset's characteristics and currently comprises Apache Cassandra (https://cassandra.apache.org/) and Ceph ( https://ceph.io/) object storage. The services provide data ingest, retrieval, discovery, metadata, processing, and other functionalities. LCMAP maintains a copy of Landsat Collection 1 ARD and other similarly tiled ancillary datasets that are spatially subset within the IW+DS to allow efficient retrieval and to enable large-scale CCDC processing and other algorithmic work. The ingest process is designed to avoid bringing in ARD tile observations that are already present within the IW+DS, to keep the input consistent with any prior usage while allowing CCDC to bring in new observations as they are available. Algorithmic results, products, and other intermediate data are kept on the Ceph object store arranged using a prefix structure to label the identity of the data, with the actual object names incorporating spatial concepts such as tile and chip that is a small subset of a tile and contains 100 by $10030 \mathrm{~m}$ pixels.

\section{Results and Discussion}

The LCMAP primary land cover and change products were evaluated to outline annual land cover change from 1985 to 2017 in the conterminous Unites States.

\subsection{Collection 1.0 primary land cover distribution and change}

The CONUS primary land cover mapping result and the primary confidence in 2010 are shown in Fig. 5a and b, respectively. The land cover map illustrates distributions of different land cover types across CONUS. The primary confidence is above $90 \%$ for most land cover classes, suggesting that the classification models were created with high confidence for land cover mapping for most classes in most regions. Some vegetation transition (dark green in Fig. 5b) occurs mainly in the southeast region suggesting gradual tree recovery from disturbances associated with tree harvesting. Fig. 5c and d display numbers of land cover changes and spectral changes detected by the CCDC model between 1985 and 2017. The number of land cover changes represents how many times land cover has changed from one type to another for a specific pixel. However, the number of spectral changes denotes how many times the model has detected spectral changes in a CCD time series model where spectral observations have diverged from the model predictions. These changes could relate to a change in thematic land cover or 
414 might represent more subtle conditional surface changes. The southeast region shows more 415 frequent land cover changes in the 33 years (Fig. 5c). The western part of CONUS, however, 416 contains more spectral changes than in the east. The different spatial patterns in the total number 417 of land cover changes (Fig. 5c) and detected spectral changes (Fig. 5d) suggest that not all 418 changes lead to land cover change (e.g., drought and precipitation-related changes in vegetation 419 or grassland fire). The large numbers of spectral change were mainly detected in the southern 420 grassland area.

421 Fig. 6 shows the temporal changes of areas for eight land cover classes from 1985 to 2017.

422 Among all classes, grass/shrub, tree cover, and cropland were dominant land cover types,

423 followed by wetland, water, developed, barren, and snow/ice. The land cover and change

424 datasets show that developed land has a consistent increasing trend with an $8.4 \%$ increase while 425 barren increased $9.1 \%$ between 1985 and 2017. Overall, the developed and barren areas 426 increased $2.58 \times 10^{4} \mathrm{~km}^{2}$ and $8.56 \times 10^{3} \mathrm{~km}^{2}$, respectively. Other land cover categories do not have 427 such increasing patterns. As for water, although fluctuating, it had a generally increasing trend.

428 The area of wetland had a rapid decrease before 2000 , following a relatively steady though 429 fluctuating trend. Net wetland extent declined about $0.4 \%$ from 1985 to 2017 . The grass/shrub 430 and tree cover classes both experienced consistent increasing trends before 2008 and 1995 with areas reaching about $2.85 \times 10^{6} \mathrm{~km}^{2}$ for grass/shrub and $2.14 \times 10^{6} \mathrm{~km}^{2}$ for tree in these two years These two land covers gradually decreased since then. Tree cover declines after 1996, showing a decreasing rate of $2.8 \%$ between 1985 and 2017. The cropland decreased from 1985 to 2008 and quickly increased after that. By 2017, the area of cropland reached a similar level of cropland area in 1988. Furthermore, most land cover changes are located in the southeast region where many pixels change more than one time. The changes detected by the CCD model suggest that landscape in the Midwest and west are more dynamic than in the east. Many areas experience multiple disturbances although most of these changes do not result in land cover transition.

The south ARD tile outlined in Fig. 5(a) covers the northern Dallas region, and the spatial patterns of land cover and change are shown in more detail in Fig. 7. The land cover distributions

441 in the region show that urban land expands considerably from 1985 (Fig. 7a), to 1990 (Fig. 7b), 442 and to 2016 (Fig. 7c). The land conversion was primarily from cropland and grass/shrub to 443 developed land. Lake Ray Roberts was created in the late 1980s and captured in the land cover 
444 map (Fig. 7b\&c). The lake and urban conversion are also visible in the change count from 1985 to 2016 (Fig. 7g), which mainly show as blue, suggesting a one-time conversion. On the other hand, there is almost no change in the urban center (Fig. 7g). Fig. 7 (d-f) shows high classification confidence at the urban center, water, grass/shrub, and tree cover areas, whereas cropland has relatively low confidence, indicating frequent management activities over croplands in the regions. The total pixels of different change numbers suggest that one to two change times are dominant, although some pixels change more than three times (Fig. 7h). The land cover distributions in 1985, 1990, and 2017 show an increase in developed land and decreases in cropland and grass/shrub (Fig. 7i).

The spatial patterns of land cover and change in the north ARD tile displayed in Fig. 5(a) in northern Wyoming are shown in Fig. 8. The tile covers most of Yellowstone National Park, in which tree, grass/shrub, and water are three dominant land cover types. Land cover in 1985, 1990, and 2016 (Fig. 8a-c) changed from tree to grass/shrub and back to tree cover. The primary land cover confidence layers exhibit changes as decreasing vegetation from tree to grass/shrub and increasing vegetation from grass/shrub to tree (Fig. 8d-f). For those trees and water bodies that did not experience any disturbances, their magnitudes of confidence are relatively large. The change map suggests that most forest lands experienced at least one change and some areas changed multiple times (Fig. 8g). Most changes in forest lands were related to wildland fires that occurred in the region. In 1988, 50 fires burned a mosaic covering nearly $3213 \mathrm{~km}^{2}$ in Yellowstone as a result of extremely warm, dry, and windy weather (NPS, 2021). Trees regrew in some of the burn areas and these changes could occur more than once as shown in the change map that indicates at least two changes in these areas. The total pixels of different change frequencies suggest that one to two changes were dominant and very few pixels changed more than three times (Fig. 8h). The land cover distributions in 1985, 1990, and 2017 had increases in grass/shrub after 1985 and reductions in tree cover after that (Fig. 8i).

\subsection{Validation of land cover product}

The overall accuracy between the annual reference land cover label and the LCMAP annual land cover products was calculated as $82.5 \%( \pm 0.22 \%$, standard error) when summarized for all years. Overall accuracy across the time series (1985-2017) varied within about 1.5\% annually, ranging from a high of $83 \%$ in the late 1990 s to about $82 \%$ in the late 2010 s (Fig. 9). Per class accuracies 
across CONUS ranged between $43 \%$ and $96 \%$ for user's accuracy (Table 3), with water showing the highest accuracy ( $96 \% \pm 0.5 \%$ user's accuracy and $93 \% \pm 0.7 \%$ producer's accuracy). Cropland has about $93 \%( \pm 0.3 \%)$ producer's accuracy and $70 \%( \pm 0.6 \%)$ user's accuracy. The lowest accuracies are observed for barren and wetland. The per class per year agreements show the accuracies vary slightly for each class in each year (Table 4).

\subsection{Significance of the product}

One of the biggest advances of LCMAP relative to conventional methods available to date is its approach of generating annual land change products by using the entire Landsat archive at a large geographic scale. Landsat ARD, which is the foundation for LCMAP, is effective and straightforward for tracking and characterizing the historical land changes at a pixel level over decades. Compared to conventional methods, detecting changes using all available observations enables us to date these changes as they occur. After change is detected, temporally consistent land cover products rather than stochastic changes in labels can be produced at annual intervals by conducting classification from CCD model segmented contributions

The LCMAP product suite includes five land cover change and five land surface change science products. It represents a new paradigm that consistently and continuously provides a large volume of land change information for land change monitoring, land resource management, and scientific research. In addition to primary and secondary land cover before and after changes, change segments containing spectral change time and magnitude are provided to explore the changes in land condition and could meet various user communities' needs. The LCMAP products can improve our understanding of causes, rates, and consequences of the land surface changes (Rover et al. 2020) such as forest changes caused by wildfire and insect outbreaks.

By implementing the CCDC algorithm through a system engineering approach, LCMAP provides a fully automated framework for land change monitoring. The framework can also be updated to include the latest Landsat records so that it can be used for operational continuous monitoring in a large geographic extent (Brown et al. 2020). Therefore, when new observations become available, the framework can provide timely and consistent land cover characteristics to the public.

\subsection{Limitations and challenges}


503 Although LCMAP Collection 1.0 products have been proven to be successful in detecting

various land surface changes to support research applications related to environment and ecology conditions, limitations and challenges exist. Utilizing Landsat ARD data as input provided consistent time series Landsat imagery with high level geometric and radiometric quality for implementing the CCDC method. Nevertheless, the densities of Landsat observation records varied greatly across space and time due to spatial differences in Landsat scene overlap and temporal coverage, as well as regional differences in contamination by clouds, cloud shadows, and snow. The change detection accuracies of CCD models were highly influenced by the temporal frequency of available observations. Zhou et al. (2019) found that using harmonized Landsat- 8 and Sentinel-2 (HLS) data increased the temporal frequency of the data and thus enhanced the ability to model seasonal variation and derived better change detection results than using Landsat data alone. Integrating multi-mission data could provide the opportunity to enhance change detection, especially for the land cover types that are highly dynamic or in frequently cloudy/snowy areas.

Providing only eight general land cover classes and their changes in LCMAP Collection 1.0 products limits the usage of the product in some applications that need a higher level of thematic land cover detail. For example, shrub and grass are two major vegetation types and have different ecological functions but they are not delineated separately in LCMAP Collection 1.0 products. Lack of measurement of grassland-shrub transition constrains the study of shrub encroachment, which is a symptom of land degradation.

Adopting NLCD 2001 as the training data source efficiently provided abundant training samples to deliver land cover product with high classification accuracy. However, these training data were randomly selected from the NLCD land cover product, suggesting errors could potentially be carried over to the training samples due to potential errors in the training source. Besides uncertainties in training data, some obvious challenges such as class definitional differences between pasture/hay and grassland between NLCD and LCMAP could potentially be carried over to the LCMAP land cover product. Implementing training data by reducing uncertainties and potential errors in a more consistent and accurate way is critical to strengthen land cover classification and to improve the scientific quality of LCMAP products in the future. 
532 There are apparent shifts in some land cover types, especially in snow/ice and barren (Fig.6), and a decline in overall agreement (Fig.9) in 2017, the last year of the Collection 1.0 product. The last year's product usually is provisional because limited Landsat observations are available at the end of a time series. The CCDC requires at least 24 clear observations to create full models for change detection and classification. Without sufficient clear observations, the algorithm could not produce model break accurately. Therefore, in the last year of a time series, the rulebased assignment is implemented to label land cover for these pixels that do not have enough observations to build a time series model. Both primary and secondary land cover classes are assigned from the last identified primary and secondary classes.

\section{Data Availability}

The LCMAP products generated in this paper are available at https://earthexplorer.usgs.gov/ (LCMAP, 2021). All LCMAP land change products are mosaiced for the conterminous United States in the GeoTIFF format. Find exact data as described here at https://doi.org/10.5066/P9W1TO6E. The reference dataset used for the product validation is also available at https://www.sciencebase.gov/catalog/item/5e57e965e4b01d50924a93f6 or https://doi.org/10.5066/P98EC5XR (Pengra et al., 2020b).

\section{Conclusions}

The continuous Landsat observations spanning from the 1980s to the present, new generations of change detection and classification models, and systems capable of processing large volume data are offering unprecedented opportunities to characterize land cover and detect land surface change consistently and accurately. Additionally, the collection of reference data used to validate land cover products provides validation result for each land cover category annually. To capture the variability of landscape condition and its responses to different disturbances, land cover and land surface change datasets need to be produced over a large geographic scale. The LCMAP has produced a suite of land change product in $30 \mathrm{~m}$ resolution including the reference dataset in the United States. In that context, LCMAP was developed to generate an essential dataset to meet broad scientific research and resource management needs. Using the CCDC algorithm and 
561 Landsat ARD to determine whether change has occurred at any given point in the observation

562

563 record, LCMAP produced annual land cover and change datasets for the conterminous United States in a robust manner. These new datasets and the novel production systems will allow for new generation of research and applications in connecting time series remote sensing observations with land surface change at a much finer scale than previously possible.

Supplement. The supplement related to this article is attached.

\section{Author contributions.}

KS conducted PyCCD programming for CCD/CCDC models. ZZ developed the original MATLAB version of CCD/CCDC programs. JH participated in reference data collection. DW and QZ assisted in data integration tasks. GX analysed the data and wrote the manuscript with contributions from all co-authors.

Completing interests. The authors declare that they have no conflict of interest.

\section{Acknowledgements.}

Any use of trade, firm, or product names is for descriptive purposes only and does not imply endorsement by the U.S. Government. Qiang Zhou and Congcong Li's work were performed under Work performed under USGS contract 140G0119C0001. 


\section{References}

Anderson, J. R., Hardy, E.E., Roach, J.T., and Witmer, R.E.: A land use and land cover classification system for use with remote sensor data, Geological Survey Professional Paper, 964, 1-28, 1976.

Boryan, C., Yang, Z., Mueller, R., and \& Craig, M.: Monitoring US agriculture: the US department of agriculture, national agricultural statistics service, cropland data layer program, Geocarto International, 26, 341-358, 2011.

Brown, J. F., Tollerud, H. J., Barber, C. P., Zhou, Q., Dwyer, J. L., Vogelmann, J. E., Loveland, T. R., Woodcock, C. E., Stehman, S. V., Zhu, Z., Pengra, B. W., Smith, K., Horton, J. A., Xian, G., Auch, R. F., Sohl, T. L., Sayler, K. L., Gallant, A. L., Zelenak, D., Reker, R. R., and Rover, J.: Lessons learned implementing an operational continuous United States national land change monitoring capability: The Land Change Monitoring, Assessment, and Projection (LCMAP) approach, Remote Sensing of Environment, 238, 111356, 2020.

Bullock, E. L., Woodcock, C. E., and Holden, C. E.: Improved change monitoring using an ensemble of time series algorithms, Remote Sensing of Environment, 238, 2020.

Chen, J., Liao, A., Cao, X., Chen, L., Chen, Z., He, C., Han, G., Peng, S., Lu, M., and Zhang, W.: Global land cover mapping at $30 \mathrm{~m}$ resolution: A POK-based operational approach, ISPRS journal of photogrammetry and remote sensing : official publication of the International Society for Photogrammetry and Remote Sensing, 103, 7-27, 2015.

Chen, T. and Guestrin, C.: XGBoost, Proceedings of the 22nd ACM SIGKDD International Conference on Knowledge Discovery and Data Mining, 785-794, 2016.

Cohen, W. B., Yang, Z., and \& Kennedy, R.: Detecting trends in forest disturbance and recovery using yearly Landsat time series: 2 . TimeSync - Tools for calibration and validation, Remote Sensing of Environment, 114, 2911-2924, 2010.

Dwyer, J. L., Roy, D. P., Sauer, B., Jenkerson, C. B., Zhang, H. K., and Lymburner, L.: Analysis Ready Data: Enabling Analysis of the Landsat Archive, Remote Sensing, 10, 1363, 2018. Erb, K. H., Luyssaert, S., Meyfroidt, P., Pongratz, J., Don, A., Kloster, S., Kuemmerle, T., Fetzel, T., Fuchs, R., Herold, M., Haberl, H., Jones, C. D., Marin-Spiotta, E., McCallum, I., Robertson, E., Seufert, V., Fritz, S., Valade, A., Wiltshire, A., and Dolman, A. J.: Land management: data availability and process understanding for global change studies, Glob Chang Biol, 23, 512-533, 2017.

Foley, J. A., DeFries, R., Asner, G.P., Barford, C., Bonan, G., Carpenter, S.R., Chapin, F.S., Coe, M.T., Daily, G.C., Gibbs, H.K., Helkowski, J.H., Holloway, T., Howard, E.A., Kucharik, C.J., Monfreda, C., Patz, J.A., Colin Prentice, I., Ramankutty, N., Synder, P.K.: Global consequences of land use, Science, 309, 570-574, 2005.

Foley, J. A., Ramankutty, N., Brauman, K. A., Cassidy, E. S., Gerber, J. S., Johnston, M., Mueller, N. D., O'Connell, C., Ray, D. K., West, P. C., Balzer, C., Bennett, E. M., Carpenter, S. R., Hill, J., Monfreda, C., Polasky, S., Rockstrom, J., Sheehan, J., Siebert, S., Tilman, D., and Zaks, D. P.: Solutions for a cultivated planet, Nature, 478, 337-342, 2011.

Friedl, M. A., Sulla-Menashe, D., Tan, B., Schneider, A., Ramankutty, N., Sibley, A., and Huang, X.: MODIS Collection 5 Global Land Cover: Algorithm Refinements and Characterization of New Datasets, Remote Sensing of Environment, 114, 168-182, 2010. Gong, P., Li, X., Wang, J., Bai, Y., Chen, B., Hu, T., Liu, X., Xu, B., Yang, J., Zhang, W., and and Zhou, Y.: Annual maps of global arifical impervious areas (GAIA) between 1985 and 2018, Remote Sensing of Environment, 236, 111510, 2020. 
Hansen, M. C., Potapov, P.V., Moore, R., et al.: High-resolution global maps of 21stcentury forest cover change, Science, 342, 850-853, 2013.

Homer, C., Dewitz, J., Jin, S., Xian, G., Costello, C., Danielson, P., Gass, L., Funk, M., Wickham, J., Stehman, S., Auch, R., and Riitters, K.: Conterminous United States land cover change patterns 2001-2016 from the 2016 National Land Cover Database, ISPRS Journal of Photogrammetry and Remote Sensing, 162, 184-199, 2020.

Jin, S., Yang, L., Danielson, P., Homer, C., Fry, J., and Xian, G.: A comprehensive change detection method for updating the National Land Cover Database to circa 2011, Remote Sensing of Environment, 132, 159-175, 2013.

Kennedy, R. E., Yang, Z., Braaten, J., Copass, C., Antonova, N., Jordan, C., and Nelson, P.: Attribution of disturbance change agent from Landsat time-series in support of habitat monitoring in the Puget Sound region, USA, Remote Sensing of Environment, 166, 271-285, 2015.

LCMAP, LCMAP Collection 1 Science Products [data]. https://doi.org/10.5066/P9W1TO6E, 2021. Li, X., Zhou, Y., Meng, L., Asrar, G. R., Lu, C., and Wu, Q.: A dataset of $30 \mathrm{~m}$ annual vegetation phenology indicators (1985-2015) in urban areas of the conterminous United States, Earth System Science Data, 11, 881-894, 2019.

$\mathrm{Li}, \mathrm{X}$., Zhou, Y., Zhu, Z., and Cao, W.: A national dataset of $30 \mathrm{~m}$ annual urban extent dynamics (1985-2015) in the conterminous United States, Earth System Science Data, 12, 357-371, 2020. NPS, 2021. Fire - Yellowstone National Park,

https://www.nps.gov/yell/learn/nature/fire.htm\#: :text=Number\%20in\%20Yellowstone,human\% 2Dcaused $\% 20$ fires $\% 20$ were $\% 20$ suppressed.\&text=The $\% 20$ number $\% 20$ of $\% 20$ fires $\% 20$ has, $70 \%$ 2C285\%20acres\%20in\%20Yellowstone\%20burned. Accessed in April 27, 2021.

Pengra, B. W., Stehman, S. V., Horton, J. A., Dockter, D. J., Schroeder, T. A., Yang, Z., and Loveland, T. R.: Quality control and assessment of interpreter consistency of annual land cover reference data in an operational national monitoring program, Remote Sensing of Environment, 238, 111261, 2020a.

Pengra, B.W., Stehman, S.V., Horton, J.A., and Wellington, D.F., 2020, Land Change Monitoring, Assessment, and Projection (LCMAP) Version 1.0 Annual Land Cover and Land Cover Change Validation Tables: U.S. Geological Survey data release, [data], https://doi.org/10.5066/P98EC5XR, 2020b.

Picotte, J. J., Dockter, D., Long, J., Tolk, B., Davidson, A., and \& Peterson, B.: LANDFIRE remap prototype mapping effort: Developing a new framework for mapping vegetation classification, change, and structure, Fire, 2, 35, 2019.

Reid, W. V., Chen, D., Goldfarb, L., Hackmann, H., Lee, Y. T., Mokhele, K., Ostrom, E., Raivio, K., Rockstrom, J., Schellnhuber, H. J., and Whyte, A.: Earth System Science for Global Sustainability: Grand Challenges, Science, 330, 916-917, 2010.

Szantoi, Z., Geller, G. N., Tsendbazar, N.-E., See, L., Griffiths, P., Fritz, S., Gong, P., Herold, M., Mora, B., and Obregón, A.: Addressing the need for improved land cover map products for policy support, Environmental Science \& Policy, 112, 28-35, 2020.

Tibshirani, R.: Regression shrinkage and selection via the lasso, Journal of the Royal Statistical Society: Series B (Methodological), 58, 267-288, 1996.

Turner II, B. L., Lambin, E. F., and and Reeberg, A.: The emergence of land change science for global environmental change and sustainability, Proceedings of the National Academy of Sciences of the United States of America, 104, 20666-20671, 2007. 
Wulder, M. A., Coops, N. C., Roy, D. P., White, J. C., and Hermosilla, T.: Land cover 2.0, International Journal of Remote Sensing, 39, 4254-4284, 2018.

Zhou, Q., Tollerud, H. J., Barber, C. P., Smith, K., and and Zelenak, D.: Training data selection for annual land cover classification for the land change monitoring, assessment, and projection (LCMAP) initiative, Remote Sensing, 12, 699, 2020.

Zhu, Z., Gallant, A. L., Woodcock, C. E., Pengra, B., Olofsson, P., Loveland, T. R., Jin, S., Dahal, D., Yang, L., and R.F., a. A.: Optimizing selection of training and auxiliary data for operational land cover classification for the LCMAP initiative, ISPRS Journal of Photogrammetry and Remote Sensing 122, 206-221, 2016.

Zhu, Z., Wang, S., and and Woodcock, C. E.: Improvement and expansion of the Fmask algorithm: Cloud, cloud shadow, and snow detection for Landsats 4-7, 8, and Sentinel 2 images, Remote Sensing of Environment, 159, 269-277, 2015a.

Zhu, Z. and Woodcock, C. E.: Automated cloud, cloud shadow, and snow detection in multitemporal Landsat data: An algorithm designed specifically for monitoring land cover change, Remote Sensing of Environment, 152, 217-234, 2014a.

Zhu, Z. and Woodcock, C. E.: Continuous change detection and classification of land cover using all available Landsat data, Remote Sensing of Environment, 144, 152-171, 2014b. Zhu, Z. and Woodcock, C. E.: Object-based cloud and cloud shadow detection in Landsat imagery, Remote Sensing of Environment, 118, 83-94, 2012.

Zhu, Z., Woodcock, C. E., Holden, C., and and Yang, Z.: Generating synthetic Landsat images based on all available Landsat data: Predicting Landsat surface reflectance at any given time., Remote Sensing of Environment, 162, 67-83, $2015 \mathrm{~b}$. 


\section{Caption of Table}

Table 1 LCMAP land cover product specifications

Table 2 NLCD land cover cross-walked to LCMAP land cover

Table 3. Confusion matrix for CONUS (all years combined) where cell entries represent percent of CONUS area. Overall accuracy is $82.5 \%( \pm 0.22 \%)$. Standard errors for user's and producer's accuracies are shown in parentheses and $n$ is the number of sample pixels for each row and column.

Table 4 Overall per class agreement in percentage between 1985 and 2017

\section{Caption of Figure}

Figure 1 Landsat ARD tile grids for the conterminous U.S.

Figure 2 Overall procedures of the CCD algorithm.

Figure 3. Figure 3. NLCD 2001 land cover (a), cross-walked LCMAP land cover classes (b), LCMAP land cover eroded by one pixel (c), zoomed in cross-walked land cover from NLCD 2001 (d), and zoomed in LCMAP land cover classes eroded by one pixel (e). The color legends represent NLCD land cover class and LCMAP primary land cover (LCPRI).

Figure 4 CCD change detection and segmentation using Landsat blue, green, red, near-infrared, short-wave infrared (SWIR) 1, short-wave infrared (SWIR) 2, and thermal bands. Blue dots are all available clear Landsat records in each year. The horizontal lines in different colors represent land cover classes labeled by the algorithm. The vertical lines show model break dates. The back line is the model fits. The high-resolution images show landscape conditions in 2007 and 2013.

Figure 5 Illustration of the LCMAP product: (a) Primary land cover in 2010, (b) Primary land cover confidence in 2010, (c) total number of land cover changes from 1985 to 2017, and (d) total number of changes detected from 1985 to 2017.

Figure 6 Areal variations of eight primary land cover types from 1985 to 2017 in CONUS.

Figure 7 Primary land cover and confidences in 1985 (a) and (d), 1990 (b) and (e), 2016(c) and (f), change in 1985-2017 (g), total pixels of different change (h), and areas of different land cover in the three times for the ARD tile 16_14 (i).

Figure 8 Primary land cover and confidences in 1985 (a) and (d), 1990 (b) and (e), 2016 (c) and (f), and change in 1985-2017 (g), total pixels of different change (h), and areas of different land cover in the three times for the ARD tile9_6 (i).

Figure 9 Overall agreement between LCMAP primary land cover and reference data across CONUS. The cross lines represent $+/$ - one standard errors. 
Table 1 LCMAP land cover product specifications

\begin{tabular}{l|l|l}
\hline Code & Land Cover Class & \\
\hline 1 & Developed
\end{tabular}

\section{Description}

Areas of intensive use with much of the land covered with structures (e.g., high-density residential, commercial, industrial, mining, or transportation), or less intensive uses where the land cover matrix includes vegetation, bare ground, and structures (e.g., low-density residential, recreational facilities, cemeteries, transportation/utility corridors, etc.), including any land functionality related to the developed or built-up activity.

\begin{tabular}{|c|c|c|}
\hline 2 & Cropland & $\begin{array}{l}\text { Land in either a vegetated or unvegetated state } \\
\text { used in production of food, fiber, and fuels. } \\
\text { This includes cultivated and uncultivated } \\
\text { croplands, hay lands, orchards, vineyards, and } \\
\text { confined livestock operations. Forest } \\
\text { plantations are considered as forests or } \\
\text { woodlands (Tree Cover class) regardless of } \\
\text { the use of the wood products. }\end{array}$ \\
\hline 3 & Grass/Shrub & $\begin{array}{l}\text { Land predominantly covered with shrubs and } \\
\text { perennial or annual natural and domesticated } \\
\text { grasses (e.g. pasture), forbs, or other forms of } \\
\text { herbaceous vegetation. The grass and shrub } \\
\text { cover must comprise at least } 10 \% \text { of the area } \\
\text { and tree cover is less than } 10 \% \text { of the area. }\end{array}$ \\
\hline 4 & Tree Cover & $\begin{array}{l}\text { Tree-covered land where the tree cover } \\
\text { density is greater than } 10 \% \text {. Cleared or } \\
\text { harvested trees (i.e. clearcuts) will be mapped } \\
\text { according to current cover (e.g. Barren, } \\
\text { Grass/Shrub). }\end{array}$ \\
\hline 5 & Water Bodies & $\begin{array}{l}\text { Areas covered with water, such as streams, } \\
\text { canals, lakes, reservoirs, bays, or oceans. }\end{array}$ \\
\hline 6 & Wetland & $\begin{array}{l}\text { Lands where water saturation is the } \\
\text { determining factor in soil characteristics, } \\
\text { vegetation types, and animal communities. } \\
\text { Wetlands are composed of mosaics of water, } \\
\text { bare soil, and herbaceous or wooded vegetated } \\
\text { cover. }\end{array}$ \\
\hline 7 & Ice and Snow & $\begin{array}{l}\text { Land where accumulated snow and ice does } \\
\text { not completely melt during the summer period } \\
\text { (i.e. perennial ice/snow). }\end{array}$ \\
\hline 8 & Barren & $\begin{array}{l}\text { Land comprised of natural occurrences of } \\
\text { soils, sand, or rocks where less than } 10 \% \text { of } \\
\text { the area is vegetated. }\end{array}$ \\
\hline
\end{tabular}


Table 2 NLCD land cover cross-walked to LCMAP land cover

\begin{tabular}{ll}
\hline NLCD Value & $\begin{array}{l}\text { LCMAP } \\
\text { Value }\end{array}$ \\
\hline Water & Water \\
$\begin{array}{l}\text { Ice/Snow } \\
\text { Developed, open space; Developed, low intensity; Developed medium } \\
\text { intensity; Developed, high intensity }\end{array}$ & $\begin{array}{l}\text { Ice and Snow } \\
\text { Developed }\end{array}$ \\
Barren & \\
Deciduous forest, Evergreen forest, Mixed forest & Barren \\
Shrub/Scrub, Grassland/Herbaceous & Tree Cover \\
Hay/Pasture, Cultivated crops & Grass/Shrub \\
Woody wetland, Emergent herbaceous wetland & Cropland
\end{tabular}


Table 3. Confusion matrix for CONUS (all years combined) where cell entries represent percent of CONUS area. Overall accuracy is $82.5 \%( \pm 0.22 \%)$. Standard errors for user's and producer's accuracies are shown in parentheses and $n$ is the number of sample pixels for each row and column.

\begin{tabular}{|c|c|c|c|c|c|c|c|c|c|c|c|}
\hline Map & Devel & Crop. & $\begin{array}{l}\text { Grass } \\
\text { /Shrub }\end{array}$ & Tree & Water & Wetland & $\begin{array}{l}\text { Ice/ } \\
\text { Snow }\end{array}$ & Barren & Total & $\begin{array}{l}\text { User } \\
\text { (SE) }\end{array}$ & $n$ \\
\hline Devel. & 3.000 & 0.139 & 0.321 & 0.377 & 0.024 & 0.035 & & 0.001 & 3.896 & $\begin{array}{l}77 \\
(1.2)\end{array}$ & 32102 \\
\hline Crop. & 0.918 & 16.527 & 5.061 & 0.799 & 0.027 & 0.368 & & 0.003 & 23.702 & $\begin{array}{l}70 \\
(0.6)\end{array}$ & 195283 \\
\hline $\begin{array}{l}\text { Grass } \\
\text { /Shrub }\end{array}$ & 0.368 & 0.757 & 30.649 & 2.599 & 0.045 & 0.229 & & 0.332 & 34.980 & $\begin{array}{l}88 \\
(0.3)\end{array}$ & 288197 \\
\hline Tree & 0.340 & 0.143 & 1.414 & 23.387 & 0.049 & 0.579 & & 0.006 & 25.917 & $\begin{array}{l}90 \\
(0.3)\end{array}$ & 213531 \\
\hline Water & 0.013 & 0.008 & 0.048 & 0.024 & 4.788 & 0.067 & & 0.020 & 4.968 & $\begin{array}{l}96 \\
(0.5)\end{array}$ & 40932 \\
\hline Wetland & 0.062 & 0.129 & 0.361 & 0.944 & 0.172 & 3.688 & & 0.001 & 5.357 & $\begin{array}{l}69 \\
(1.3)\end{array}$ & 44136 \\
\hline $\begin{array}{l}\text { Ice/Sno } \\
\mathrm{w}\end{array}$ & & & 0.004 & 0.004 & & 0.004 & 0.012 & 0.004 & 0.028 & $\begin{array}{l}43 \\
(18.7)\end{array}$ & 231 \\
\hline Barren & 0.072 & 0.005 & 0.501 & 0.013 & 0.056 & 0.012 & & 0.492 & 1.151 & $\begin{array}{l}43 \\
(2.8) \\
\end{array}$ & 9485 \\
\hline Total & 4.772 & 17.707 & 38.358 & 28.149 & 5.162 & 4.981 & 0.012 & 0.859 & 100.00 & & \\
\hline $\begin{array}{l}\text { Prod } \\
\text { (SE) }\end{array}$ & $\begin{array}{l}63 \\
(1.3)\end{array}$ & $\begin{array}{l}93 \\
(0.3)\end{array}$ & $\begin{array}{l}80 \\
(0.4)\end{array}$ & $\begin{array}{l}83 \\
(0.4)\end{array}$ & $\begin{array}{l}93 \\
(0.7)\end{array}$ & $\begin{array}{l}74 \\
(1.2)\end{array}$ & $\begin{array}{l}100 \\
(0)\end{array}$ & $\begin{array}{l}57 \\
(3.2)\end{array}$ & & & \\
\hline$n$ & 39319 & 145886 & 316027 & 231916 & 42530 & 41042 & 99 & 7078 & & & \\
\hline
\end{tabular}


https://doi.org/10.5194/essd-2021-202

Preprint. Discussion started: 13 August 2021

(c) Author(s) 2021. CC BY 4.0 License.

Table 4 Overall per class agreement in percentage between 1985 and 2017

\begin{tabular}{|c|c|c|c|c|c|c|c|c|}
\hline $\begin{array}{l}\text { Overall Per } \\
\text { Class } \\
\text { Agreement }\end{array}$ & Developed & Cropland & Grass/Shrub & Tree & Water & Wetland & Snow/Ice & Barren \\
\hline 1985 & 66 & 80 & 83 & 87 & 95 & 72 & 60 & 49 \\
\hline 1986 & 67 & 80 & 83 & 87 & 95 & 72 & 60 & 49 \\
\hline 1987 & 68 & 80 & 83 & 86 & 95 & 72 & 60 & 49 \\
\hline 1988 & 68 & 80 & 83 & 87 & 95 & 72 & 60 & 49 \\
\hline 1989 & 68 & 80 & 84 & 87 & 95 & 72 & 60 & 48 \\
\hline 1990 & 68 & 80 & 84 & 87 & 95 & 72 & 60 & 48 \\
\hline 1991 & 68 & 80 & 84 & 87 & 95 & 72 & 60 & 49 \\
\hline 1992 & 69 & 80 & 84 & 87 & 95 & 71 & 60 & 50 \\
\hline 1993 & 69 & 80 & 84 & 87 & 95 & 71 & 60 & 49 \\
\hline 1994 & 69 & 80 & 84 & 87 & 95 & 71 & 60 & 49 \\
\hline 1995 & 70 & 80 & 84 & 87 & 95 & 72 & 60 & 49 \\
\hline 1996 & 69 & 80 & 84 & 87 & 95 & 72 & 60 & 48 \\
\hline 1997 & 70 & 80 & 84 & 87 & 95 & 72 & 60 & 49 \\
\hline 1998 & 70 & 80 & 84 & 87 & 94 & 72 & 60 & 48 \\
\hline 1999 & 70 & 80 & 84 & 87 & 95 & 72 & 60 & 48 \\
\hline 2000 & 70 & 80 & 84 & 87 & 95 & 72 & 60 & 48 \\
\hline 2001 & 70 & 80 & 84 & 87 & 95 & 72 & 60 & 49 \\
\hline 2002 & 70 & 80 & 84 & 86 & 95 & 72 & 60 & 49 \\
\hline 2003 & 70 & 80 & 84 & 87 & 94 & 71 & 60 & 48 \\
\hline 2004 & 69 & 80 & 84 & 86 & 94 & 71 & 60 & 48 \\
\hline 2005 & 70 & 80 & 84 & 86 & 94 & 71 & 60 & 49 \\
\hline 2006 & 70 & 79 & 84 & 86 & 94 & 71 & 60 & 49 \\
\hline 2007 & 70 & 79 & 84 & 86 & 94 & 71 & 60 & 50 \\
\hline 2008 & 70 & 79 & 84 & 86 & 94 & 71 & 60 & 49 \\
\hline 2009 & 70 & 79 & 84 & 86 & 94 & 71 & 60 & 49 \\
\hline 2010 & 70 & 79 & 84 & 86 & 94 & 71 & 60 & 50 \\
\hline 2011 & 70 & 79 & 84 & 86 & 94 & 71 & 60 & 51 \\
\hline 2012 & 70 & 79 & 83 & 86 & 94 & 71 & 60 & 50 \\
\hline 2013 & 69 & 79 & 83 & 86 & 94 & 71 & 60 & 50 \\
\hline 2014 & 69 & 79 & 83 & 86 & 94 & 71 & 60 & 50 \\
\hline 2015 & 69 & 79 & 83 & 86 & 94 & 71 & 60 & 50 \\
\hline 2016 & 69 & 79 & 83 & 86 & 94 & 71 & 60 & 50 \\
\hline 2017 & 69 & 78 & 83 & 85 & 94 & 70 & 60 & 49 \\
\hline
\end{tabular}




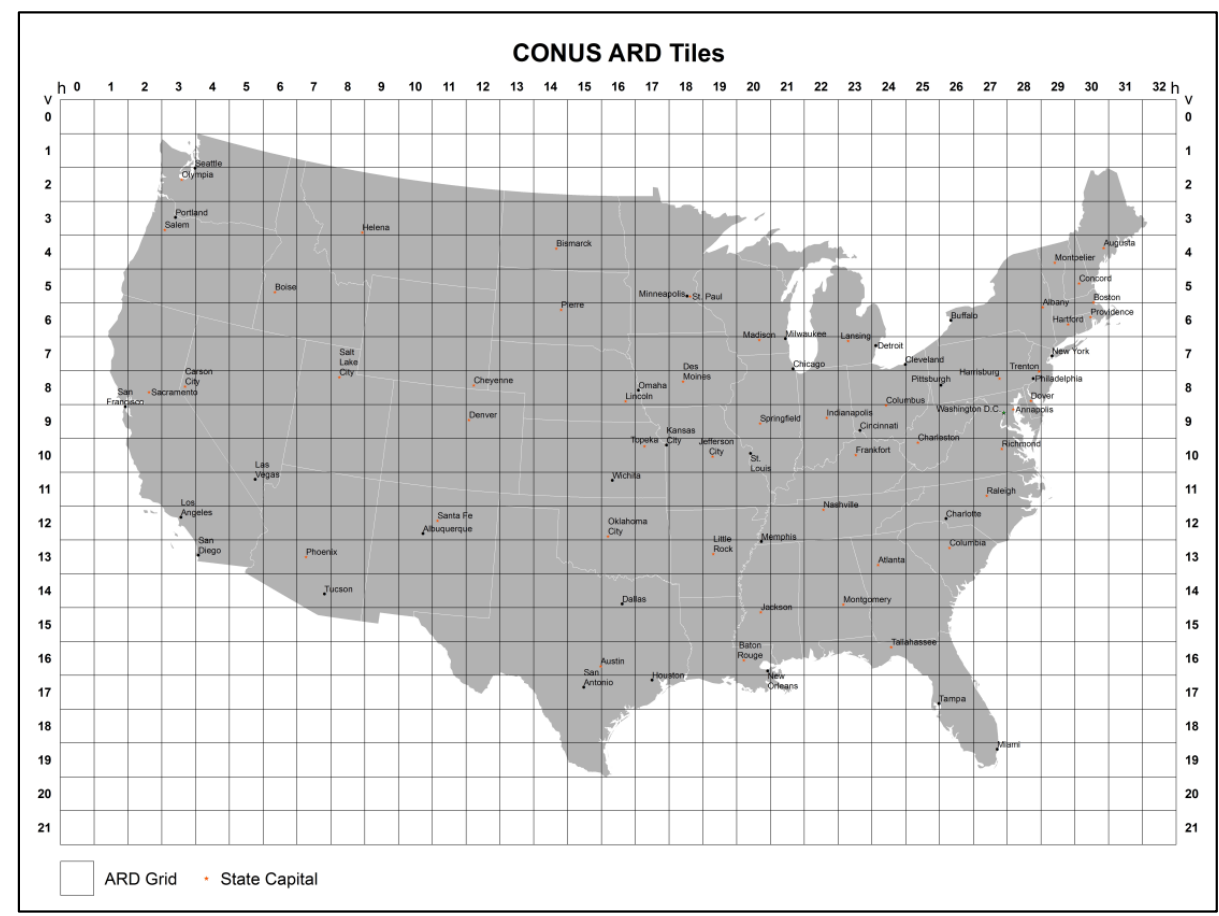

Figure 1 Landsat ARD tile grids for the conterminous U.S. 
https://doi.org/10.5194/essd-2021-202

Preprint. Discussion started: 13 August 2021

(c) Author(s) 2021. CC BY 4.0 License.

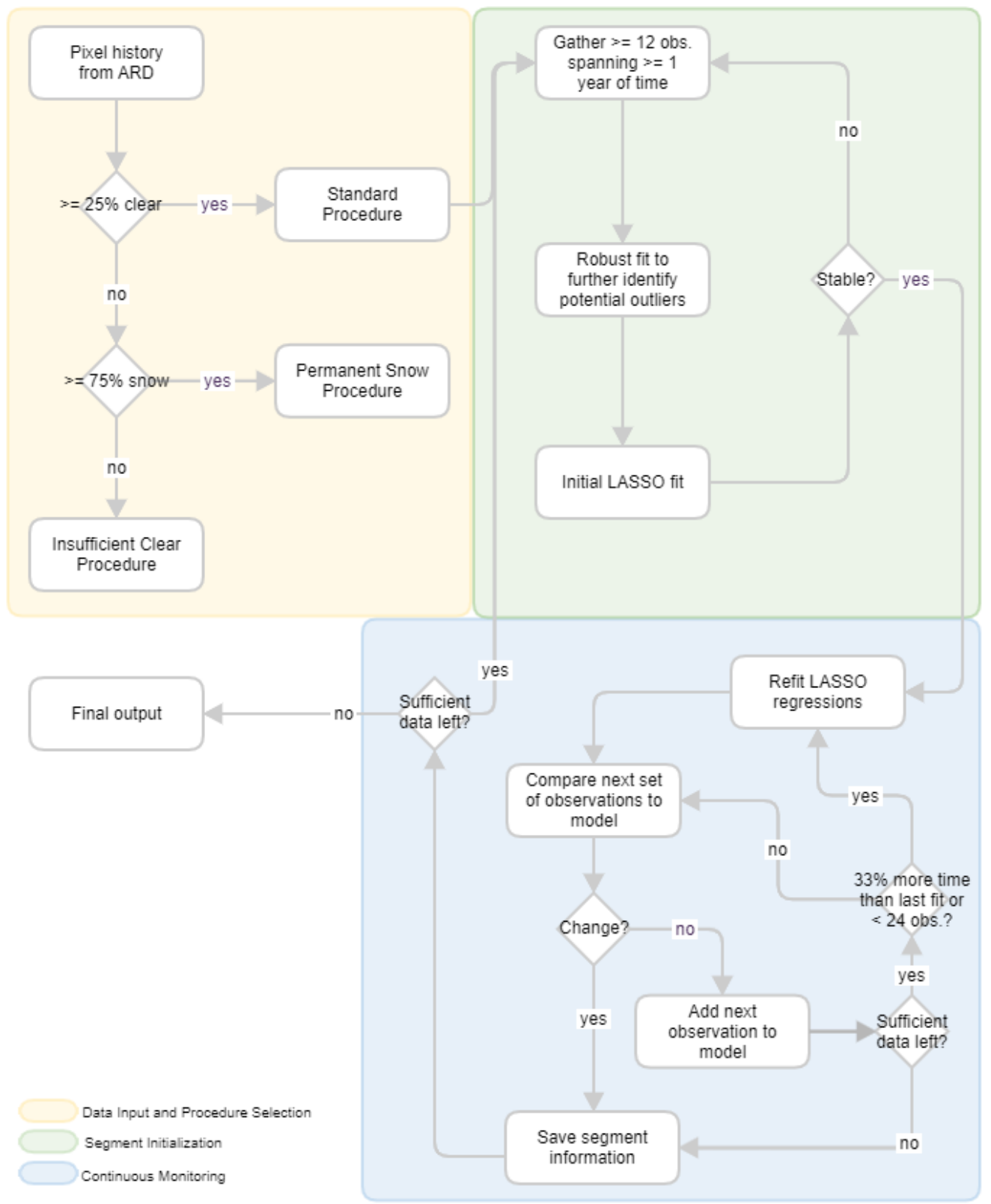

Figure 2 Overall procedures of the CCD algorithm. 
(a)
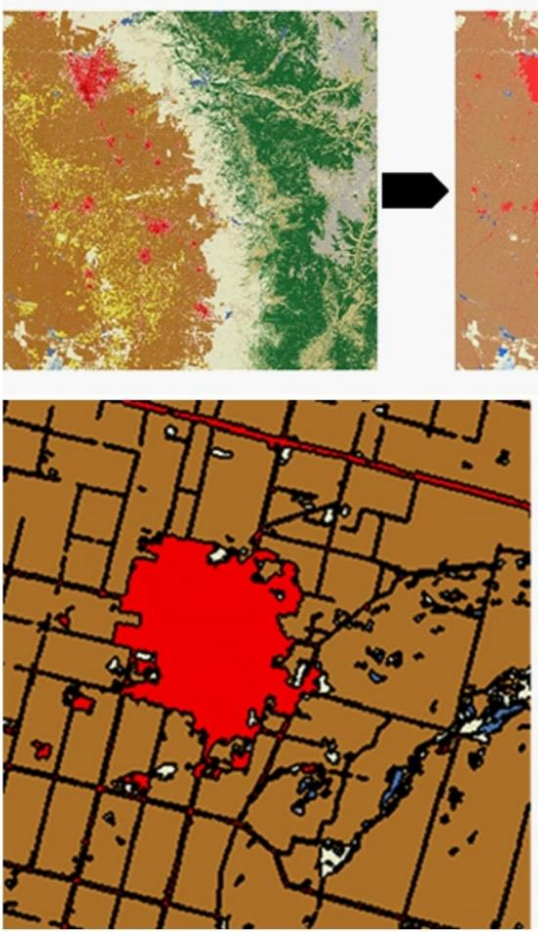

(d) (b)
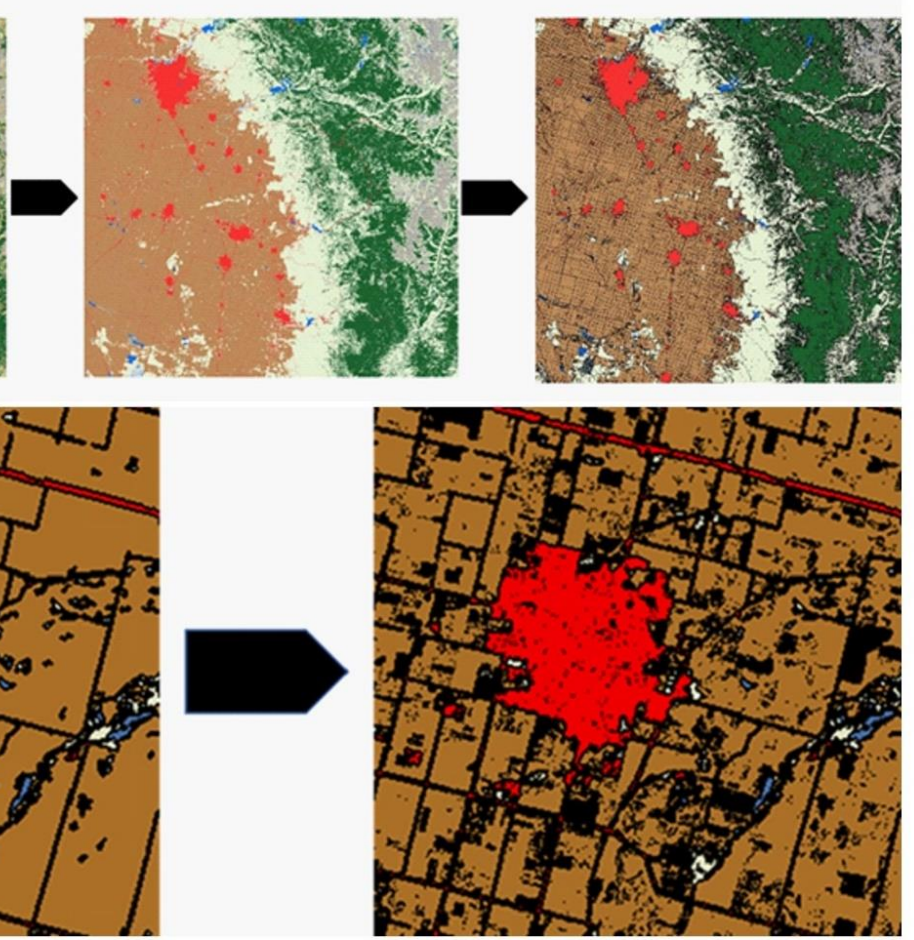

(e)

LCPRI

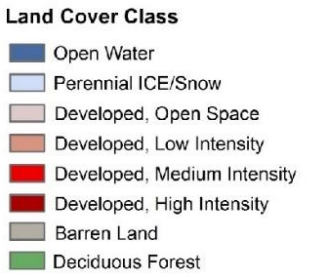

Evergreen Forest

$\square$ Mixed Forest

$\square$ Shrub/Scrub

$\square$ Grassland

$\square$ Hay/Pasture

Cultivated Crops

$\square$ Woody Wetlands

$\square$ Emergent Herbaceous Wetlands

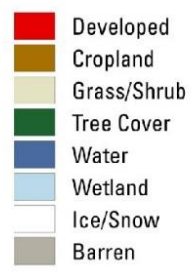

Figure 3. NLCD 2001 land cover (a), cross-walked LCMAP land cover classes (b), LCMAP land cover eroded by one pixel (c), zoomed in cross-walked land cover from NLCD 2001 (d), and zoomed in LCMAP land cover classes eroded by one pixel (e). The color legends represent NLCD land cover class and LCMAP primary land cover (LCPRI). 

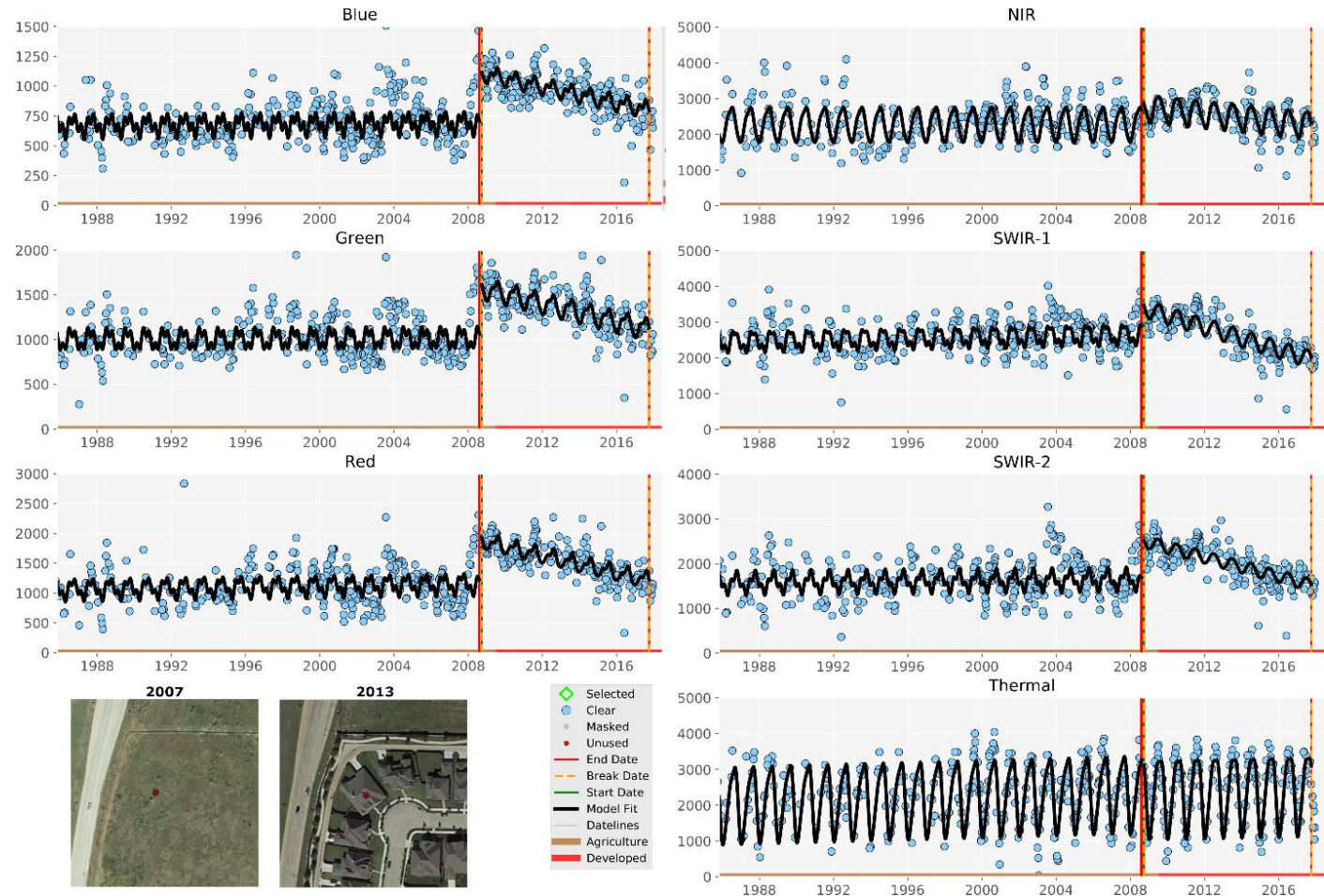

Figure 4 CCD change detection and segmentation using Landsat blue, green, red, near-infrared, short-wave infrared (SWIR) 1, short-wave infrared (SWIR) 2, and thermal bands. Blue dots are all available clear Landsat records in each year. The horizontal lines in different colors represent land cover classes labeled by the algorithm. The vertical lines show model break dates. The back line is the model fits. The high-resolution images show landscape conditions in 2007 and 2013. 

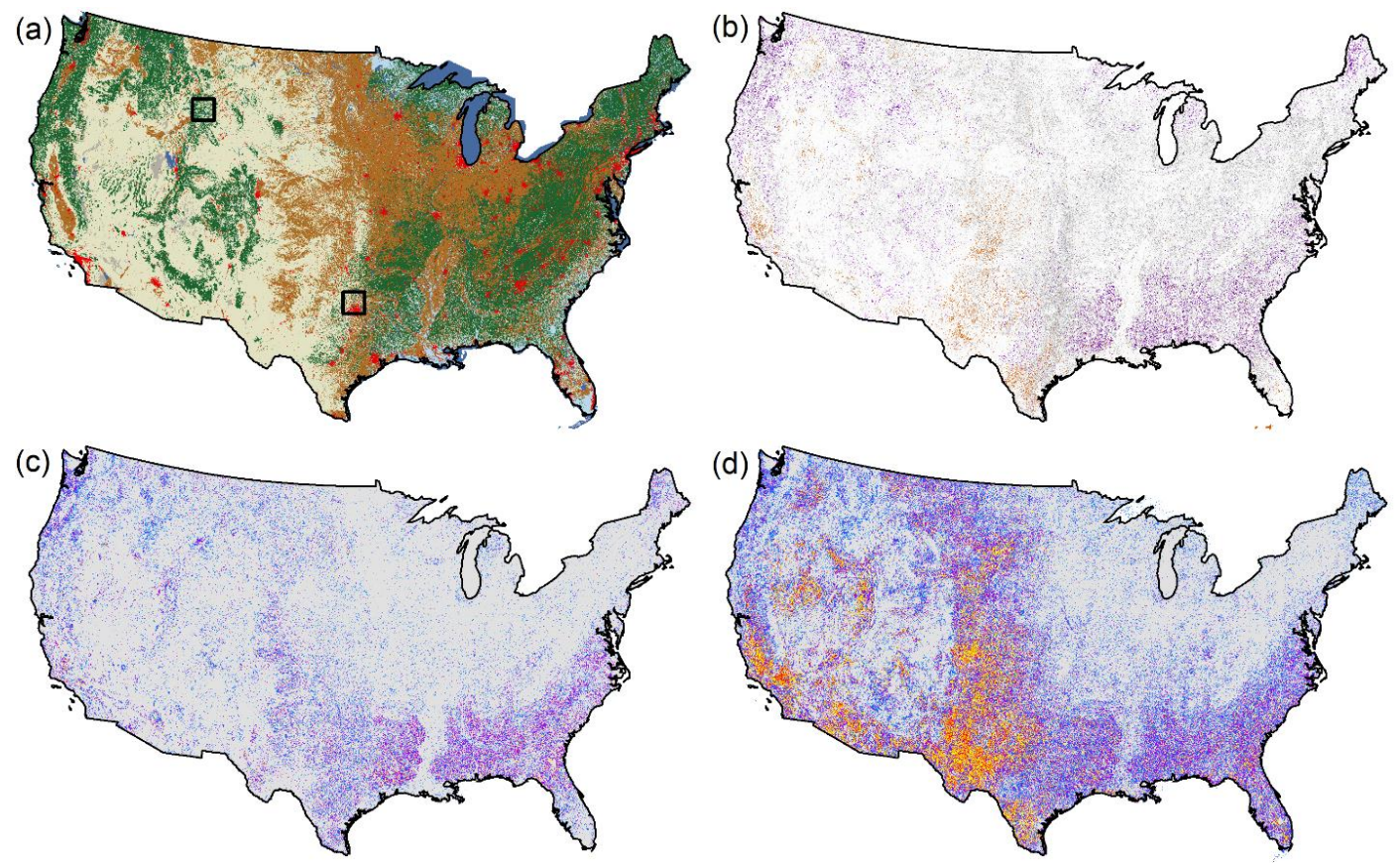

(a) Land cover

(b) Measure of Confidence

(c) (d) Count of changes
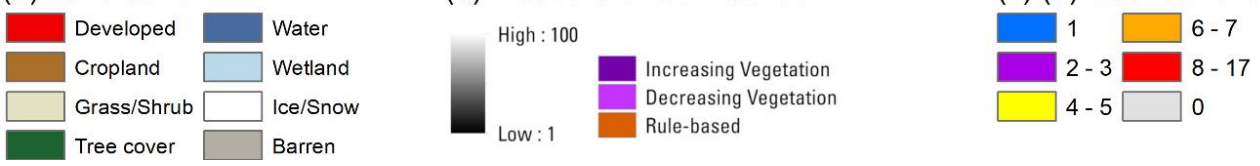

Figure 5 Illustration of the LCMAP product: (a) Primary land cover in 2010, (b) Primary land cover confidence in 2010, (c) total number of land cover changes from 1985 to 2017, and (d) total number of changes detected from 1985 to 2017. 
https://doi.org/10.5194/essd-2021-202

Preprint. Discussion started: 13 August 2021

(c) Author(s) 2021. CC BY 4.0 License.
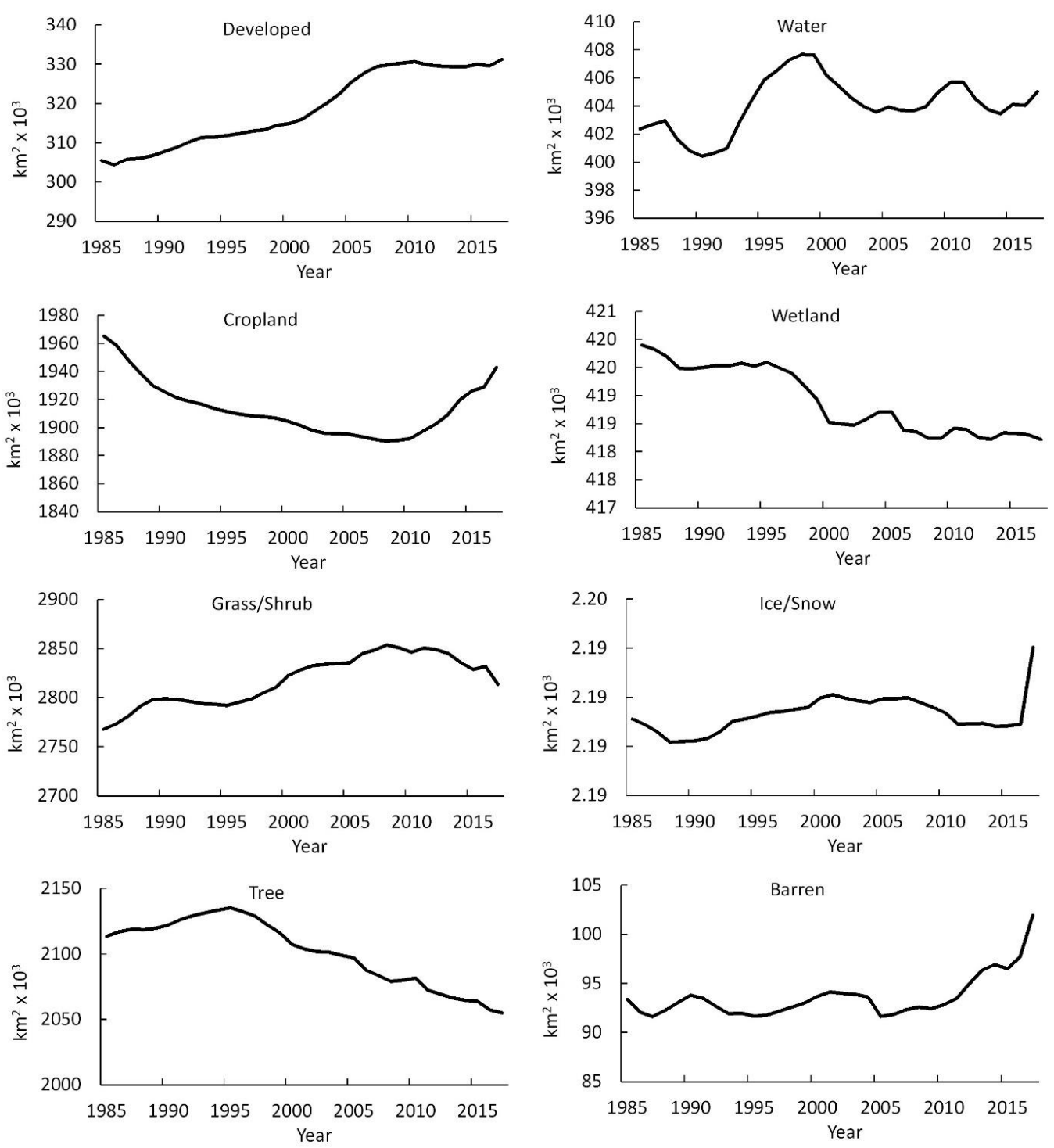

Figure 6 Areal variations of eight primary land cover types from 1985 to 2017 in CONUS. 


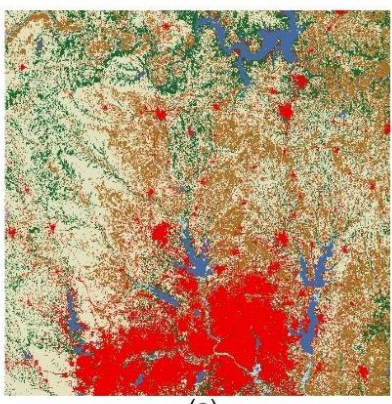

(a)

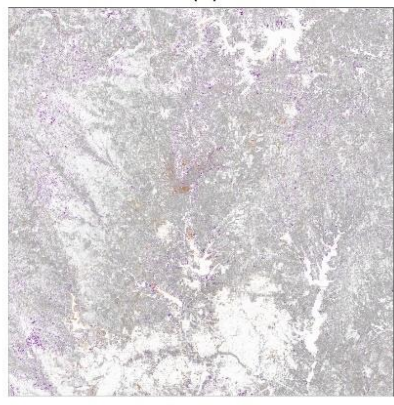

(d)

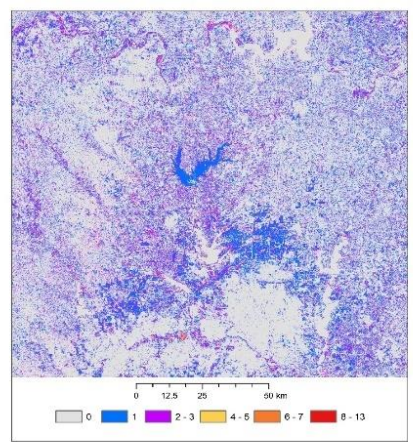

(g)

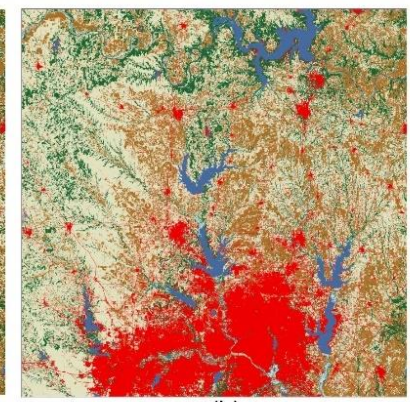

(b)

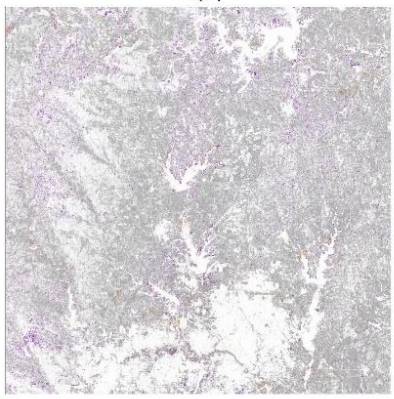

(e)

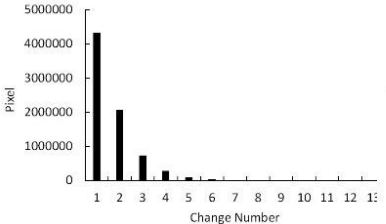

(h)

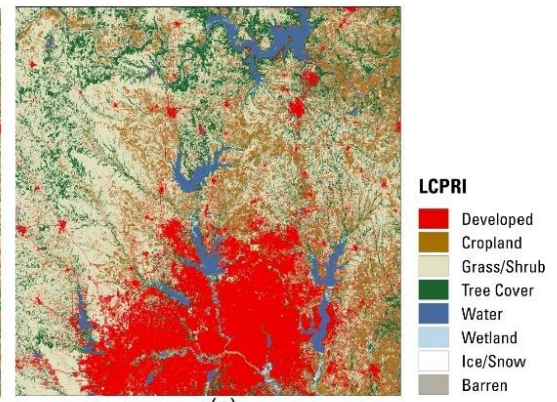

(c)

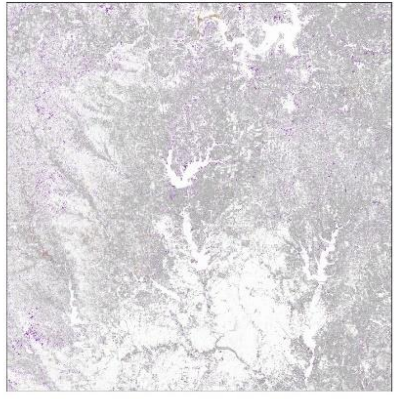

(f)

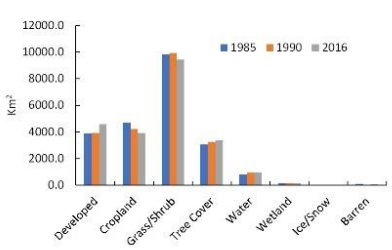

(i)

Figure 7 Primary land cover and confidences in 1985 (a) and (d), 1990 (b) and (e), 2016(c) and (f), change in 1985-2017 (g), total pixels of different change (h), and areas of different land cover in the three times for the ARD tile 16_14 (i). 


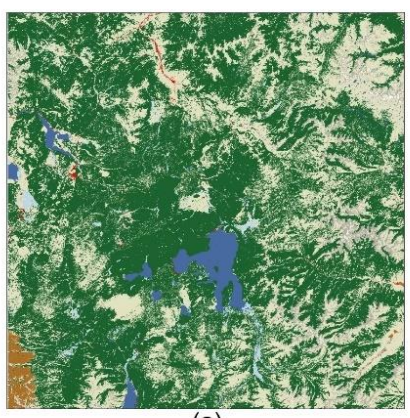

(a)

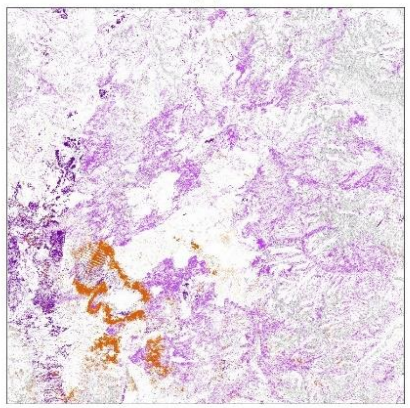

(d)

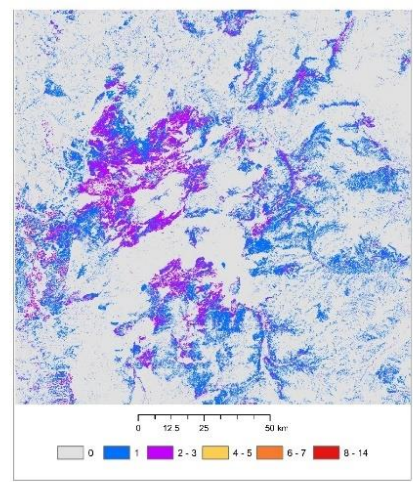

(g)

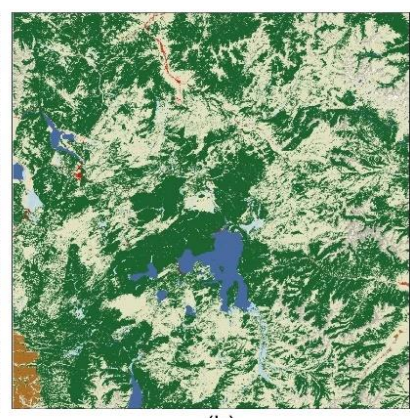

(b)

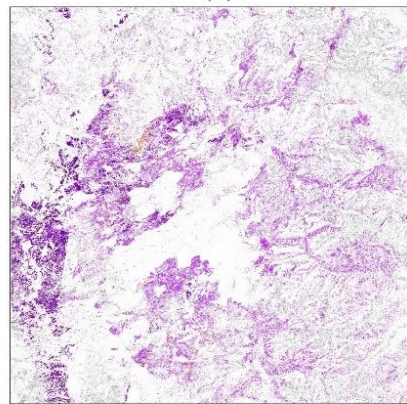

(e)

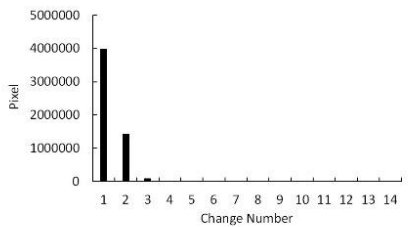

(h)

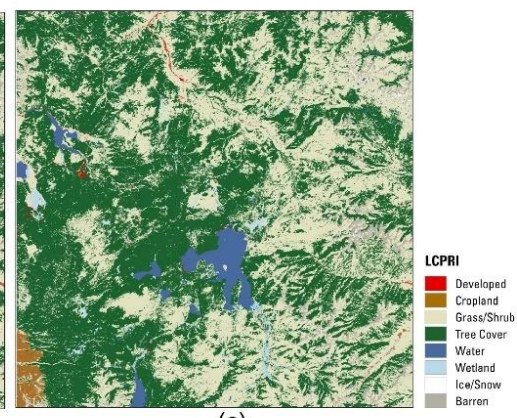

(c)

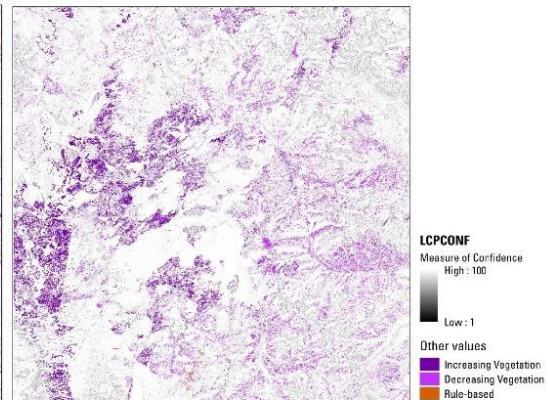

(f)

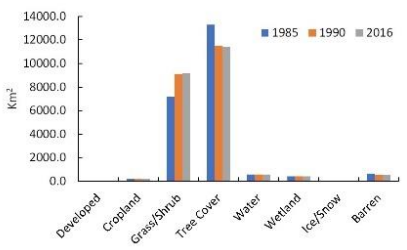

(i)

Figure 8 Primary land cover and confidences in 1985 (a) and (d), 1990 (b) and (e), 2016 (c) and (f), and change in 1985-2017 (g), total pixels of different change (h), and areas of different land cover in the three times for the ARD tile9_6 (i). 


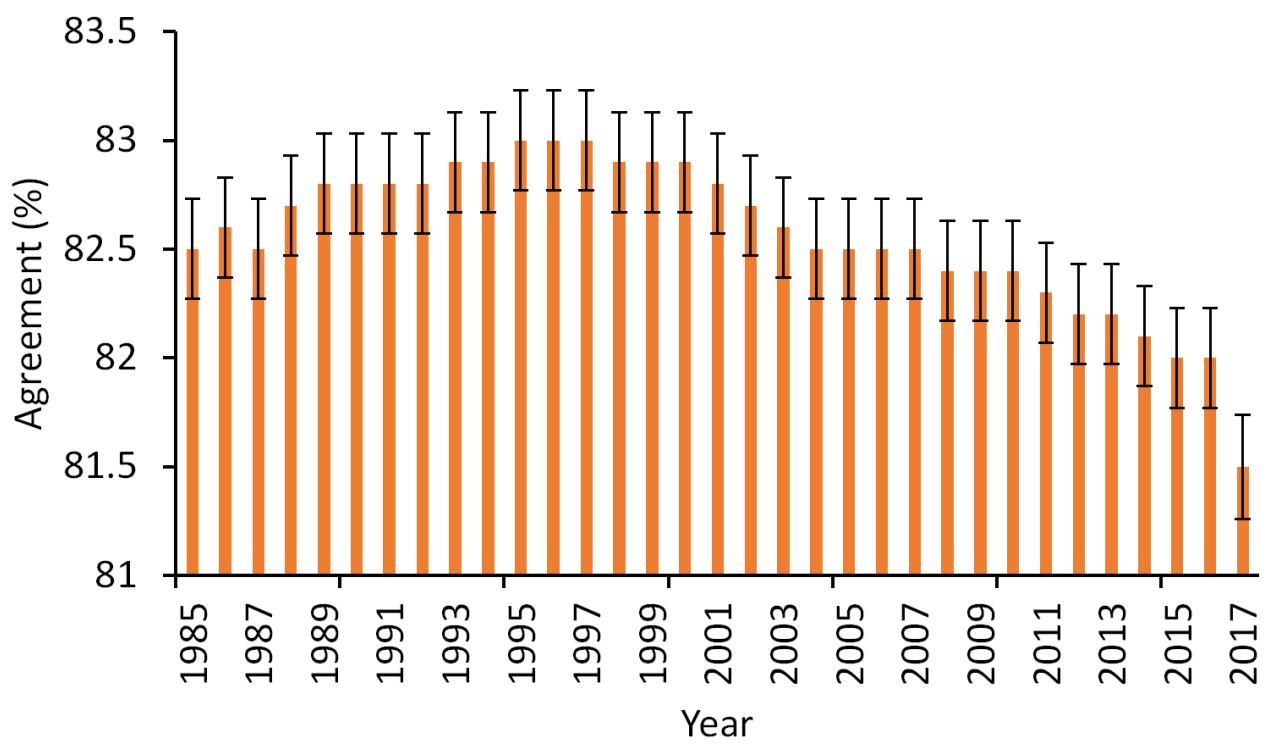

Figure 9 Overall agreement between LCMAP primary land cover and reference data across CONUS. The cross lines represent $+/$ - one standard errors. 